\title{
Concepto teológico de recepción con vistas a su aplicación al desarrollo posterior al Concilio Vaticano II
}

\author{
Rodrigo Polanco F. \\ FACULTAD DE TEOLOGÍA \\ PONTIFICIA UNIVERSIDAD CATÓLICA DE CHILE
}

El hecho de la «recepción» en la Iglesia, en sus múltiples procesos, es una realidad tan básica y fundamental que no deja de sorprender el que su discusión teológica, al menos en ambiente católico, esté todavía bastante poco desarrollada ${ }^{1}$. Sin embargo, siendo la recepción una realidad profundamente antropológica -la existencia humana es un permanente dar y recibir-, y siendo el acto de fe, fundamentalmente, un acto de acogida -recepción- libre y personal de la autocomunicación de Dios al hom$b^{2} e^{2}$, se puede pensar que su escaso desarrollo teológico en la conciencia eclesial actual se debe, justamente, a la amplitud de este concepto, lo cual lo hace difuso y no fácil de abarcar; a la vez que puede ser enfrentado desde muy diversas perspectivas que se relacionan, al mismo tiempo, con otros conceptos teológicos. Todo lo cual ha hecho que después de muchos siglos, solo en los últimos cincuenta años ha vuelto a ser considerado in recto como tema de estudio ${ }^{3}$.

\section{Significado inicial}

Recepción, del latín receptio-recipere, etimológicamente significa recibir, guardar para sí, aceptar o acoger, y básicamente designa el proceso, ge-

1 Cf. H. FIsCHER, «Rezeption in ihrer Bedeutung für Leben und Lehre der Kirche», en Zeitschrift für Theologie und Kirche 89 (1990) 100-103.

2 Cf. A. Antón, «La "recepción” en la Iglesia y eclesiología»: en Gregorianum 77 (1996) 60.

3 C..H. РотtмeYer, «Rezeption und Gehorsam-Aktuelle Aspekte der wiederendeckten Realität "Rezeption"”, en Glaube als Zustimmung. Zur Interpretation kirchlicher Rezeptionsvorgänge (QD 131) (Herder, Freiburg 1991), 51-57. 
neralmente lento, personal o grupal en donde un individuo o una comunidad acoge y hace suyo algo que es considerado un bien para quienes lo aceptan. Fundamentalmente encontramos tres ámbitos en los que se está desarrollando una intelección de este concepto. En un sentido amplio y general, designa el proceso natural de desarrollo que implica asumir bienes de la cultura ajenos o no todavía apropiados, en la esfera de la propia conciencia y existencia. "Toda evolución del espíritu tiene entonces un carácter de recepción». Es un proceso tan antiguo como el ser humano, pero que ahora se le conoce como recepción ${ }^{4}$.

A nivel eclesial y teológico podemos entender la recepción como «un acontecimiento esencial en la Iglesia y para la Iglesia en la medida en que con él se designa el modo y manera en que se transmite el mensaje de la revelación de Cristo a la fe viva de los creyentes y en la medida en que estos lo reciben", puesto que implicará siempre una forma de aceptación libre y personal. "Y en la medida en que la fe es un acontecimiento dinámico, el proceso de recepción se realiza de continuo" ${ }^{5}$. Se refiere tanto al acto de acoger la revelación con la fe personal, como a la vivencia de esa misma fe con otros y con todos los creyentes en un intercambio permanentemente enriquecedor ${ }^{6}$. Anteriormente, sin embargo, su comprensión había estado limitada, al interior de la Iglesia, al proceso de acoger las decisiones de los concilios en la vida de la comunidad y a toda la tensión que presenta la acogida y obediencia no unívoca que la comunidad le presta a las enseñanzas ordinarias y extraordinarias del magisterio. El tema se había centrado en torno a la cuestión de la obediencia de los fieles y al papel definitorio de la jerarquía. Siendo esto parte de la recepción, no agota con mucho el proceso completo.

En la perspectiva del movimiento ecuménico también se ha venido desarrollando un concepto propio de recepción. Se trató, en un primer momento, de «la aceptación por parte de una iglesia del consenso teológico alcanzado con otra iglesia», a partir de las comisiones teológicas bi/ multilaterales que se han establecido para ese efecto. Ese proceso se comprendió de modo análogo a la forma que tenía la Iglesia en la antigüedad de recibir las decisiones de un concilio. Sustentado en una eclesiología de comunión, el proceso de recepción se comprendía en los primeros

\footnotetext{
H. Fischer, «Rezeption, Kirchliche II»: Theologische Realenzyclopädie, 29, 143.

5 W. BeInert, «Recepción», Diccionario de Teología Dogmática, 581.

6 Cf. A. Antón, «La "recepción” en la Iglesia», 61.
} 
siglos como algo más que un acto jurídico, por lo cual cada iglesia reconocía en las decisiones conciliares un punto de llegada autoritativo, pero también un punto de partida. Paulatinamente, sin embargo, esa concepción «ecuménica» se ha visto en la necesidad de «reconocer la fe y la vida eclesial de la otra iglesia como auténticamente cristiana» ${ }^{7}$. Esto último ha traído innegables dificultades. En efecto, hoy las iglesias, de hecho, están separadas, por lo tanto, la recepción entendida así, pasa primero por el reconocimiento de la otra como iglesia verdadera, lo cual implica, a su vez, estar de acuerdo en lo que significa consenso en materia eclesial, es decir, qué es lo que constituye necesariamente a una comunidad en Iglesia, qué es necesario, qué es suficiente, quién lo ratifica, etc. ${ }^{8}$. En pocas palabras, es un tema de concepción de Iglesia. Pero todo eso es ya tema que nos excede en este trabajo.

Volviendo a considerar el tema desde una perspectiva teológica católica, un concepto tan amplio como el recién expresado puede llegar a decir a la vez mucho y nada. Por eso es bueno comenzar con una primera definición descriptiva de lo que hoy entendemos por recepción como concepto teológico, es decir, recepción en la Iglesia y como acto eclesial. Podemos comprenderla9 como un largo, diversificado y lento proceso

Th. Rausch, «Reception Past and Present», en Theological Studies 47 (1986) 497.

8 Cf. A. Birmelé, «La réception comme exigence oecuménique», en G. Evans - M. Gourgues, Communion et reunión. Mélanges J.-M. R. Tillard (University Press, Leuven 1995), 75-94.

9 Me baso en -y cito-, la noción descriptiva de A. ANTón «La "recepción” en la Iglesia y eclesiología», en Gregorianum 77 (1996) 445-446, que él elabora luego de revisar una buena cantidad de definiciones que se han dado sobre este complejo proceso (cf. pág. 64-72). Fundamentalmente el autor destaca tres artículos paradigmáticos: Y. Congar, "La "réception" comme réalité ecclésiologique», en Revue des Sciences Philosophiques et Théologiques 56 (1972) 369-403; J. Willebrands, "The ecumenical dialogue and its reception»: OneCh 21 (1985) 217-225; K. Rahner, «Ekklesiologische Grundlagen», en Handbuch der Pastoraltheologie, I, 119. Pero también la definición presentada por A. Antón es deudora de los siguientes artículos: H. Pottmeyer, Rezeption und Gehorsam; W. Beinert, "Die Rezeption und ihre Bedeutung für Leben und Lehre der Kirche», en Glaube als Zustimmung. Zur Interpretation kirchlicher Rezeptionsvorgänge (QD 131) (Herder, Freiburg 1991), 15-49; E. Lanne, «La notion ecclésiologique de réception» Revue Théologique de Louvain 25 (1994) 30-45; Th. Rausch, Reception Past and Present; M.J. Himes, "The Ecclesiological Significance of the Reception Doctrine»: Heythop Theological Journal 33 (1992) 146-160; E. Kilmartin, Reception in History: An Ecclesiological Phenomenon and its Significance: JEcumSt 21 (1984) 34-54; A.M. Wittig, «Konzil 
-que va más allá de un acto formal o jurídico de simple obediencia o acogida pasiva-, a través del cual toda comunidad cristiana eclesial, compuesta por pastores y fieles, orgánica y jerárquicamente estructurada bajo carismas y ministerios diversificados y complementarios, y en constante relación de comunión y mutua participación con las demás y con todas las comunidades e iglesias particulares, recibe, acoge y hace suyo, como un bien para sí, bajo la asistencia del Espíritu Santo, el mensaje siempre nuevo -y que acontece también hoy- del Evangelio. Esta acogida, a la vez personal y comunitaria, libre y consciente, explícita e implícita, como acto de adhesión por la fe de la inteligencia y la voluntad (DV 5), está referida a todo el contenido de la Revelación, trasmitido por la Escritura y la Tradición viva de la Iglesia, bajo la conducción del Magisterio de la Iglesia, aceptándolo como elemento auténtico, útil y necesario de la fe católica, en continuidad con la Iglesia apostólica. Se recibe, entonces, todo lo que la Iglesia «es y cree», lo que «a Iglesia con su enseñanza, su vida, su culto conserva y transmite a todas las edades» (DV 8). Esto es, lo que los pastores proponen como enseñanza auténtica, la vida, celebración, santidad y misión de los fieles cristianos, y todas las «formas de expresión y testimonio del mensaje cristiano, que son fruto del sensus fidei de la totalidad de los fieles y se transmiten» a partir de múltiples y complementarios procesos que se han sintetizado normalmente en «las instituciones eclesiales, la práctica litúrgico-sacramental», en un credo y reflexión dogmático-pastoral, en una identidad y misión y en una práctica ético-existencial que dan cuenta del ser cristiano eclesial.

\section{Procesos de recepción en la historia de la Iglesia antigua}

Puede ayudar a perfilar mejor un concepto tan existencial y omniabarcante el revisar algunos momentos especialmente relevantes de la histo-

und Rezeption. Die Annahme von Glaubensentscheidungen eines Konzils durch das Kirchenvolk als Akt des geschuldeten Glaubensgehorsam oder als Beitrag zur Gültigkeit der Entscheidungen»: AnHCon 20 (1988) 245-250; F. Wolfinger, «Die Rezeption theologischer Ansichten und ihre theologische Bedeutung: Von der Einsicht zur Verwirklichung»: Catholica 31 (1977) 207-216; A. Houtepen, «Reception, Tradition, Communion», en M. Thurian, (ed.), Ecumenical Perspectives on Baptism, Eucharist and Ministry (Geneva 1983), 140-160; J.-M.R TIllard, "Fondement ecclésiologiques de la 'réception' oecuménique»: Toronto Jounal of Theology 3 (1987) 28-40; H. CHadwick, General Synod, Report of Proceedings 16/1 (February 1985) 75. 
ria de la Iglesia, en donde se pueden apreciar más notoriamente procesos de recepción. En primer lugar, lo vemos claramente expuesto en la paulatina composición de las Escrituras, hasta la elaboración definitiva del canon eclesial en torno al siglo segundo-cuarto ${ }^{10}$.

Es sumamente complejo, y tal vez imposible, tratar de reconstruir detalladamente la composición del AT. Sin embargo es posible afirmar que ese desarrollo tiene un punto crucial en torno al inicio del siglo IV a.C., con el comienzo de lo que hoy llamamos judaísmo, el cual se desarrollará en una cierta continuidad hasta la destrucción del templo en el año 71 d.C. En aquel momento se confeccionó lo esencial de lo que hoy llamamos AT. Ese proceso, en época persa, trajo consigo toda una elaboración teológica de carácter retrospectivo: «Se refiere a las vivencias precedentes y al mismo tiempo las fundamenta dándoles un significado, una significación nueva ciertamente, que llegó a ser parte integrante e irrenunciable de aquellas vivencias» ${ }^{11}$. Y eso es claramente un proceso de recepción de una historia vivida, en cuanto, a partir de un material previamente elaborado, se re-piensa la propia existencia en las nuevas circunstancias históricas. De igual modo, la elaboración del canon veterotestamentario es un proceso de recepción ya que, en torno al siglo I d.C. la cuestión canónica no estaba totalmente resuelta. El hecho que, por una parte, el cristianismo se defina por el uso de la versión de los LXX, mientras que el judaísmo rabínico, en torno a Jamnia, se defina por un «canon palestinense» está mostrando que la dilucidación del mismo canon fue también una cuestión de recepción de textos, en cuanto sagrados, a partir de una fe previamente acogida. Fueron, por una parte, el Evangelio de Cristo de las comunidades cristianas y, por otra, la Torá oral (=Misná y Midrás) del judaísmo rabínico los que filtraron, reinterpretaron y completaron el AT o la Torá escrita, en esos años, en un proceso auténtico de/o de no recepción ${ }^{12}$.

El NT, además de ser en parte resultado de un largo proceso de recepción (con una historia de la tradición/redacción bastante compleja),

10 W. Rusch, Reception. An Ecumenical Opportunity (The Lutheran World Federation, Philadelphia 1988), 43.

11 M. Liverani, Oltre la Bibbia. Storia antica di Israele (Roma - Bari ' 2007 ), 402.

12 Cf. R. Trevijano, La Biblia en el cristianismo antiguo. Prenicenos. Gnósticos. Apócrifos (Verbo Divino, Estella 2001), 113-115. 
testimonia múltiples formas de recepción ${ }^{13}$ y acogida ${ }^{14}$ en la vida cristiana: «¿Qué tienes que no hayas recibido (๕̌ $\lambda \alpha \beta \varepsilon \varsigma)$ de Dios?» (1Cor 4,7). El mismo Hijo toma para sí la condición humana con toda su historia social

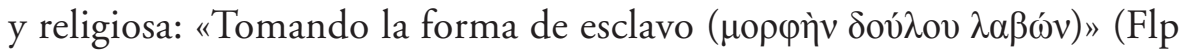
$2,7)$. Y «vino a los suyos, mas los suyos no lo recibieron. Pero a todos los

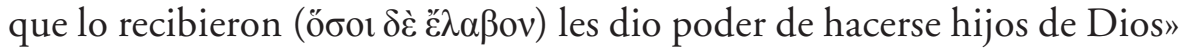
(Jn 1,11-12). Durante su ministerio público, Jesús nos invitó a acoger el

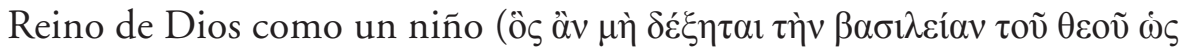
$\pi \alpha i \delta i ́ o v . .).($ Mc 10,15). Luego de su resurrección, la comunidad cristiana nace y se desarrolla precisamente a partir de la acogida del testimonio y la tradición de los apóstoles: «Al recibir ( $\pi \alpha \rho \alpha \lambda \alpha \beta o ́ v \tau \varepsilon \varsigma)$ la palabra de Dios que os predicamos, no la acogisteis $(\dot{\varepsilon} \delta \varepsilon \dot{\varepsilon} \xi \alpha \sigma \theta \varepsilon)$ como palabra de hombre, sino cual es en verdad: como palabra de Dios, que permanece activa en vosotros, los creyentes» (1Tes 2,13). Podemos comprobar igualmente que el acto de recepción va siempre por delante y constituye a la comunidad cristiana: se recibe $\left(\lambda \alpha \mu \beta \alpha{ }^{\prime} \omega \omega\right)$ el Espíritu Santo que viene de Dios (1Cor 2,12), se acoge $(\pi \alpha \rho \alpha \lambda \alpha \mu \beta \alpha ́ v \omega)$ la predicación apostólica $(1$ Cor 15,1$)$ y se recibe el bautismo (Hech 2,41). Con esto queda claro que recepción y tradición forman una unidad, "porque os trasmití

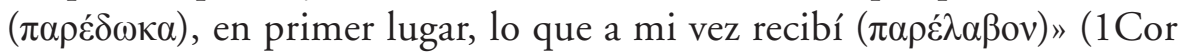

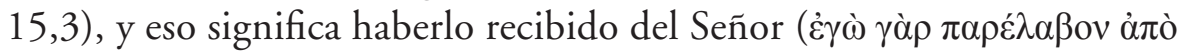

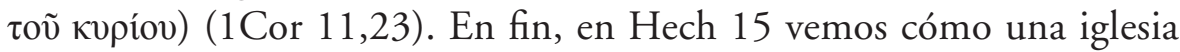
acoge y hace universal la experiencia y el mensaje de otra iglesia, a partir de los delegados enviados. "La recepción, por lo tanto, es una estructura fundamental de la vida y de la fe de la comunidad cristiana» ${ }^{15}$, según el testimonio del NT. Y «o que finalmente resulta de la recepción de la predicación apostólica por parte de todos aquellos que llegan a la conversión por obra de los apóstoles y otros primeros misioneros, es la Iglesia misma» ${ }^{16}$, como evento del Espíritu Santo que hace presente a Cristo en un encuentro personal con él ${ }^{17}$.

13 Cf. G. Delling, Art. $\lambda \alpha \mu \beta \alpha ́ v \omega, \kappa \tau \lambda$. , Theologisches Wörterbuch zum Neuen Testament 4, 5-16.

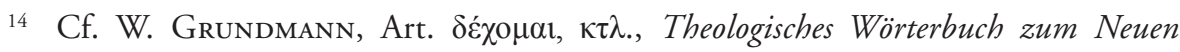
Testament 2, 49-59.

15 G. Grassmann, «Rezeption, Kirchliche I»: Theologische Realenzyklopädie 29, 134. Para este párrafo, cf. Ibídem., 132-134.

16 Th. Rausch, Reception Past and Present, 499.

17 Cf. W. Rusch, Reception, 35-36. 
Al igual que en el AT, la elaboración y discernimiento del canon neotestamentario ha sido una clara experiencia de recepción eclesial. «De una serie de escritos transmitidos en su seno con fidelidad y estima [la Iglesia] reconoce y "recibe", a través de un proceso largo de reflexión, algunos como "escritura sagrada", teniéndolos por expresión auténtica de su fe en el evento-Cristo y conformes al kerigma apostólico». Pero el reconocimiento oficial lo que hace es confirmar un consenso -una recepción- que, con diferencias más bien pequeñas y poco relevantes, se ha dado ya en las iglesias sobre «la índole sagrada de los libros canónicos ya existentes ${ }^{18}$, como se puede apreciar, por ejemplo, en las mismas palabras de los decretos que a lo largo de los siglos han fijado y luego confirmado la lista aprobada (=canónica): «Hay que tratar de las Escrituras divinas, qué es lo que ha de recibir (recipiat) la universal Iglesia Católica y qué debe evitar (vitare debeat)» (Sínodo de Roma, año 382, DH 179) ${ }^{19}$. La misma constitución Lumen gentium ${ }^{20}$ argumenta a favor del sensus fidei trayendo a colación un texto de san Agustín en donde argumenta que desde siempre y en todas partes todos los estamentos de la Iglesia han considerado divino el libro de la Sabiduría y ha merecido ser leído en la Iglesia, por lo tanto, nadie puede negar que es inspirado, ya que la fe de todo el pueblo no puede equivocarse (De praedestinatione sanctorum 14, 27 [PL 44, 980]). La recepción lo «canonizó».

El desarrollo dogmático presente en la historia de los concilios ecuménicos muestra también un verdadero camino de recepción, que en ocasiones se prolongó por un tiempo considerable, hasta que fueron más universalmente acogidos como vinculantes para la $\mathrm{fe}^{21}$ : «convocación, participación y representación de las iglesias, comunicación de sus decisiones y aceptación de las mismas por parte de la Iglesia de Roma» ${ }^{22}$ son parte integrante de este amplio proceso de recepción. Podemos recordar, por ejemplo, que la fe de Nicea (325) fue acogida más definiti-

\footnotetext{
18 A. Antón, La «recepción» en la Iglesia, 89.

19 Puede verse también el Decretum Gelasianum (S. VI) (DH 352); el Decreto para los Jacobitas (año 1442) (DH 1334); y el Concilio de Trento, Decreto sobre la aceptación de los sagrados libros y tradiciones (año 1546) (DH 1501). Cf. Y. CongaR, La 'réception' comme réalité ecclésiologique, 380-381.

20 LG 12.

21 Cf. W. BeInert, «Recepción», Diccionario de Teología Dogmática, 580.

22 A. Antón, La «recepción»en la Iglesia, 88.
} 
va y pacíficamente solo con Concilio de Constantinopla I (381), luego de varios «sínodos, excomuniones, exilios e intervenciones y violencias imperiales $»^{23}$. El mismo Concilio de Constantinopla I, fue considerado ecuménico solo cuando el símbolo Niceno-Constantinopolitano fue acogido en Calcedonia (451) como expresión más acabada de la fe auténtica de $\mathrm{Nicea}^{24}$. El Concilio de Éfeso (431), solo llegó a ser aceptado más universalmente luego de la fórmula de unión redactada por el obispo Juan de Antioquía, dos años después de celebrado el concilio ${ }^{25}$. El Concilio de Calcedonia "recibió», a su vez, la carta de San León Magno a Flaviano (Ep. 28) y dos cartas de San Cirilo de Alejandría, haciéndolas parte de lo decidido por la asamblea sinodal ${ }^{26}$. Pero también hubo no-recepción de Calcedonia por parte de la iglesia de Armenia y las iglesias Coptas de Egipto y Etiopía (de tradición monofisita), separación que dura hasta hoy. Como también había habido no-recepción de Éfeso por parte de las iglesias Asirias y Caldeas de Oriente (de tradición nestoriana ${ }^{27}$. Con todo, la recepción de los decretos conciliares se produce por un proceso multiforme, que implica tanto elaboraciones teológicas, prácticas litúrgicas y espirituales, como desarrollos pastorales. Un ejemplo clásico es el Cuarto Concilio de Letrán (1215), recibido en

23 Y. CONGAR, La «réception» comme réalité ecclésiologique, 372.

24 Cf. H. Jedin - G. Alberigo et ali (Ed.), Conciliorum Oecumenorum Decreta (EDB, Bologna 1991), 22.83-87. En las Acta Conciliorum Oecumenicorum II,1 (E. Schwartz (De Gruyter, Berlin 1932), 265-280) se narra: "Los gloriosos oficiales y el magnífico senado dijeron: «Lean en voz alta las exposición de los 150 padres». Aecio el reverendísimo archidiácono de Constantinopla leyó desde un documento: La santa fe definida por los 150 padres, en armonía con el santo y gran sínodo de Nicea: [lee el Símbolo de Constantinopla] Todos los obispos exclamaron: "Esta es la fe de todos. Esta es la fe de los ortodoxos. Así creemos todos»" ( $\left.\mathrm{N}^{\circ} 13-15\right)$.

25 Cf. H. Jedin - G. Alberigo et Alit (Ed.), Conciliorum Oecumenorum Decreta, 38.69-74.

26 "[Este Concilio] hace suyas las cartas sinodales del beato Cirilo, que fue pastor de la iglesia de Alejandría, a Nestorio y a los orientales, como adecuada... A aquella ha agregado gustosamente la carta del beatísimo y santísimo arzobispo de la grandísima y antiquísima ciudad de Roma, León, escrita al arzobispo Flaviano... ella, en efecto, está en armonía con la confesión de fe del gran Pedro" (H. JEDin G. Alberigo et alit (Ed.), Conciliorum Oecumenorum Decreta, 85).

27 Es notable constatar que en la última década del siglo pasado, luego de quince siglos, en los dos casos ha habido recepción de ambos concilios respectivamente. Esto indica lo largo que puede ser un proceso de recepción y cómo puede depender también de circunstancias históricas. 
occidente con tal fuerza, que marcó la vida de la Iglesia por sucesivos siglos, incluso "59 de sus 70 cánones pasaron al derecho eclesiástico, hasta el CIC de $1917 »^{28}$. Lo mismo se puede decir de Trento, ahora con la Iglesia de Occidente separada de la Reforma, sus decretos pasaron vigorosamente a la vida litúrgica, teológica y pastoral de la Iglesia de los siglos posteriores. «En este sentido, la recepción de un Concilio se identifica con su eficacia» ${ }^{29}$.

Podríamos exponer tantos otros ejemplos de procesos de recepción en la vida eclesial ${ }^{30}$. «Muchos sínodos locales alcanzaron por la vía de la recepción una importancia y significado de cara a la Iglesia universal» ${ }^{31}$ : clásicos ejemplos son el Sínodo XV de Cartago (418) y el II de Orange (529), ambos en torno al tema del pecado original y de la gracia, que marcaron definitivamente el desarrollo teológico posterior. En todo caso los procesos de recepción de los sínodos y concilios han sido muy variados y no lineales ${ }^{32}$, aunque "ciertamente, el reconocimiento de estos por parte de la Iglesia de Roma desempeñó muy pronto y con mucha frecuencia un papel decisivo ${ }^{33}$. Otro ejemplo se da en torno al kerygma apostólico que fue decantando paulatinamente en fórmulas de fe neotestamentarias y luego en formulas litúrgico-sacramentales que se fueron transmitiendo y recibiendo en el seno de una fe común. Todo esto dio origen a los símbolos o credos de carácter más o menos universales. Igualmente la autocomprensión de la Iglesia como comunión universal de iglesias determinó un fecundo proceso práctico de intercambio, de dar y recibir: encontramos muy recurrentemente las cartas de comunión, que eran letras concedidas por el obispo a sus fieles cuando cambiaban domicilio y que les aseguraba acogida en las iglesias en comunión con la del obispo propio $^{34}$. Entre esas cartas están también las cartas con que los obispos se informaban entre sí sobre hechos particulares de sus iglesias (elección de obispos, exclusión de herejes). Particular importancia tenía el intercambio

\footnotetext{
28 Y. Congar, La 'réception' comme réalité ecclésiologique, 374.

29 Ibídem. Para este párrafo cf. pág. 372-375.

30 Cf. E. Kilmartin, Reception in History, 40-52.

31 W. Beinert, «Recepción», Diccionario de Teología Dogmática, 580.

32 Cf. A. Grillmeier, Konzil und Rezeption. Methodische Bemerkungen zu einem Thema der ökumenischen Diskussion der Gegenwart: ThPh 3 (1970) 331-337.

33 A. Antón, La "recepción” en la Iglesia, 93.

34 Cf. M. Kent, La Iglesia. Eclesiología católica (Sígueme, Salamanca 1996), 300.
} 
de cartas sinodales en donde se comunicaban las decisiones más relevantes. También era frecuente la comunicación de la ordenación de los obispos: «la legalidad de una elección episcopal dependía también en definitiva del consentimiento de los obispos vecinos». "Cada obispo poseía un elenco de todos aquellos obispos con los que su Iglesia estaba en comunión. El elenco era actualizado constantemente» ${ }^{35}$. En fin, la paulatina formación de las grandes familias litúrgicas de oriente y occidente fue el resultado de que grandes unidades culturales se sabían poseedoras de una misma fe que podían celebrar juntos ${ }^{36}$, de modo que en un largo proceso de intercambio de formas, tradiciones, fechas, gestos, signos, se fue conformando un rico «patrimonio litúrgico, teológico, espiritual y disciplinar, distinto por cultura y circunstancia histórica de los pueblos, que se expresa en un modo de vivir la fe que es propia de cada Iglesia de propio derecho ${ }^{37}$.

\section{Comprensión de la RECEpCión EN TORNO AL FINAL DEL SEGUNdo} MILENIO

Sería interesante todavía estudiar el desarrollo que durante el segundo milenio ha tenido la comprensión del fenómeno de la recepción y la importancia que tuvieron, en ese período, diversos factores que marcaron su mismo desarrollo. Por ejemplo, las grandes divisiones de la cristiandad que fueron haciendo mucho más homogénea la Iglesia Católica, ahora prácticamente identificada con la Iglesia de occidente. Todo el trabajo misionero que, a partir del siglo VI, va siendo motivado y conducido cada vez con más fuerza por la Iglesia de Roma, lo cual hace de todo occidente un solo "gran patriarcado", en cuanto las nuevas iglesias son «hijas» de la Iglesia de Roma. Esto también ayudó a la homogenización. Y si a eso agregamos el desarrollo jurisdiccional del primado en el contexto feudal de la querella de las investiduras y los posteriores movimientos conciliaristas y galicanos que pedían una aceptación jurídica de las decisiones del magisterio, todo sumado fue influyendo en una concepción más reducida del concepto de recepción: sea entendida fundamentalmente como obediencia, sea entendida -y rechazada- como una aprobación jurídica necesaria para la validez de los actos del magisterio.

\footnotetext{
35 M. KeHL, La Iglesia. Eclesiología católica (Sígueme, Salamanca 1996), 300.

36 Cf. W. Rusch, Reception, 42.

37 CCEO, Can. 28,1. Para este párrafo cf. A. Antón, La "recepción" en la Iglesia, 87-93.
} 
Pero, en el contexto de este trabajo, no es posible siquiera mencionar algunos ejemplos al respecto.

Con todo, en el Concilio Vaticano I, momento culminante de ese desarrollo, no se perdió totalmente la reflexión sobre el tema ${ }^{38}$. En la discusión sobre el Capítulo Cuarto de la Constitución Pastor Aeternus, «Sobre el magisterio infalible del Romano Pontífice» (DH 3065-3075), aparece la cuestión acerca de si el magisterio infalible del Papa «es independiente o está ligado a la fe y al consensus de la Iglesia y de los obispos en el acto de definir». «En el debate se reivindica reiteradamente para el Papa en el ejercicio de su magisterio infalible la independencia del consensus ecclesiae docentis, pero no del sensus Ecclesiae» ${ }^{39}$. Mons. Vinzenz Gasser, como portavoz de la comisión de la Fe, aunque niega la obligatoriedad del Papa de indagar de una manera determinada el consensus, afirma sin embargo, que el Sumo Pontífice de hecho lo hace, deduciendo su enseñanza, tanto de la Escritura, de los Santos Padres, de las opiniones teológicas y de otros modos adecuados. Con esto confirma la prioridad del sensus Ecclesiae, y por tanto, la vigencia de la recepción al interno de este. Estas ideas, aunque de modo verbal indicativo, fueron recogidas posteriormente por la Constitución Pastor Aeternus (cap. $4^{\circ}$ ):

«Los Romanos Pontífices, por su parte, según lo persuadía la condición de los tiempos y de las circunstancias, ora por la convocación de Concilios ecuménicos o explorando la opinión de la Iglesia dispersa por el orbe, ora por sínodos particulares, ora empleando otros medios que la divina providencia deparaba, definieron que habían de mantenerse aquellas cosas que, con la ayuda de Dios, habían reconocido ser conformes a las sagradas Escritura y las tradiciones apostólicas. Pues no fue prometido a los sucesores de Pedro el Espíritu Santo para que por revelación suya manifestaran una nueva doctrina, sino para que, con su asistencia, santamente custodiaran y fielmente expusieran la revelación transmitida por los Apóstoles, es decir, el depósito de la fe”" (DH 3069-3070).

Este es el modo correcto de entender entonces que «las definiciones del Romano Pontífice son irreformables ex sese, non autem ex consensu Ecclesiae» (DH 3074). Quiere decir que esas definiciones «tienen valor

38 Cf. G. Grassmann, «Rezeption, Kirchliche I»: Theologische Realenzyclopädie, 29, 137.

39 A. Antón, El misterio de la Iglesia. Evolución histórica de las ideas eclesiológicas, II (BAC, Madrid 1987), 381-382. 
vinculante por sí mismas» y no necesitan de la aprobación ulterior o consentimiento de ninguna autoridad eclesial para ser válida. Se excluye entonces «un consensus» "como una condición jurídica sine qua non», un «consensus subsequens», pero no "la vinculación real del Papa al consenso de la Iglesia $»^{40}$, ni la recepción posterior de esa enseñanza, como se pudo comprobar, por ejemplo, en el caso de la respuesta de los obispos alemanes al canciller imperial alemán Otto von Bismarck (DH 3112-3116), en donde la lectura (=recepción) del dogma de la infalibilidad por parte de los obispos alemanes (estamos en el año 1875) pasó a ser una interpretación auténtica del $\operatorname{dog} \mathrm{ma}^{41}$, retomada incluso por el mismo papa Pío IX en la Carta Apostólica Mirabilis illa constantia (4 de marzo de 1875) a los obispos alemanes (DH 3117). El tema interesante aquí es que la obediencia al magisterio, incluso al infalible, no dispensa del consensus Ecclesiae, que implica siempre vida de fe acogida y compartida.

En todo caso en el contexto recién explicitado se llegó, por parte católica, a una comprensión de la recepción que se asemejaba bastante a lo que es la obediencia, si bien entendiéndola "como común adhesión de los fieles bajo la guía del sagrado magisterio» (CIC 750). Y al comprenderla de modo más reductivo -fundamentalmente dentro del ámbito jurídico-, se rechaza cualquier acto de recepción como ratificación constitutiva. En el fondo estamos hablando aquí de obediencia y no de recepción. Era necesaria entonces una vuelta a las raíces del concepto.

La Iglesia Ortodoxa ha caminado por otras vías, pero me parece que no ha logrado salir de una tensión, o incluso de una suerte de contradicción ${ }^{42}$.

«Por una parte, el Concilio ecuménico ha sido considerado siempre la más alta autoridad, y por otra parte, sus acuerdos adquieren propiamente su validez, solo cuando han sido recibidos por la Iglesia. Es la

40 A. Antón, El misterio de la Iglesia. Evolución histórica de las ideas eclesiológicas, II (BAC, Madrid 1987), 385-389. Para el párrafo cf. Ibídem., 377-389.

41 "[El Papa] está sujeto al derecho divino y vinculado al ordenamiento dado por Jesucristo a su Iglesia. El Papa no puede modificar la constitución que la Iglesia ha recibido de su divino Fundador" (Declaración colectiva de los obispos de Alemania, enero-febrero de 1875) (DH 3114).

42 Cf. W. Rusch, Reception, 51-53. 
totalidad de la Iglesia la que decide sobre la verdad de las decisiones conciliares» ${ }^{43}$.

Esta idea ha sido especialmente desarrollada por la teología eslavófila del siglo XIX, casi entendiendo que la recepción por parte de la totalidad de la Iglesia es lo que hacía vinculantes las decisiones de los concilios. Hoy día en sede ortodoxa se tiende a pensar más bien que la recepción es «una comprobación, no un acto de obligatoriedad jurídica», «es el conocimiento y la toma de conciencia de que una determinada resolución coincide y concuerda con la creencia de la Iglesia ${ }^{44}$.

«Recepción sería un efecto de la acción del Espíritu Santo en la Iglesia, acción que no se deja encerrar en una determinada forma o estructura reglamentaria, y en donde la Iglesia examina y decide, bajo la conducción del Espíritu Santo, lo que es conforme a la verdad recibida y co-

43 H. Fischer, «Rezeption, Kirchliche II»: Theologische Realenzyclopädie 29, 145. Se puede recordar el rechazo final -luego de una historia compleja, con factores de tipo político, étnico y teológico que influyeron en el desenlace final-, por parte del pueblo ortodoxo, a las decisiones del Concilio de Florencia, en torno a la reunificación de la Iglesia (Bula Laetentur caeli, de 1439). Es un caso de norecepción que invalidó la decisión previa de sus patriarcas. Cf. DH 1300-1308.

W. Beinert, «Recepción», Diccionario de Teología Dogmática, 580. «El Espíritu que reposa sin cesar en el Cuerpo de Cristo, asegura la única infalibilidad que reconoce la Iglesia ortodoxa: la de la Verdad. Y el Espíritu hace evidente la Verdad a la Iglesia, es decir, a los cristianos que hacen de la Iglesia el fundamento de su conciencia. En efecto, la formulación del dogma como una regla de fe indispensable y necesaria pertenece exclusivamente al episcopado, sobre todo cuando se reúne en concilio [... ] El Magisterio sin embargo, se contenta con reconocer y preservar una verdad en la que la Iglesia ya vivía [...] Todo concilio se afirma como tal, y toma decisiones obligatorias para los fieles. Estos deben presumir que el colegio episcopal, cuando se reúne, ha constituido verdaderamente un Concilio y proclamado la Verdad. Sin embargo los que han recibido la Unción del Espíritu, es decir, todos los fieles, no pueden recibir ciegamente por pura sumisión, una decisión episcopal o conciliar. No pueden recibir más que la Verdad, esta Verdad de la que son responsables: o mejor, no pueden recibir sino la justa expresión de una Verdad que ya es su Vida [...] La definición pertenece únicamente al Magisterio, pero todo cristiano consciente tiene el deber, en caso de incertidumbres graves, de exigir un nuevo juicio del Magisterio al que la Iglesia, esta vez, pueda responder con un amén análogo al de la epíclesis: digamos pues, que si el consenso de la Iglesia no es idéntico al amén de la epíclesis, debe llegar a ser idéntico, por un proceso histórico en el que el Espíritu puede servirse de los profetas para llamar al episcopado a su carisma, para hacer coincidir en la asamblea de los obispos el inevitable momento personal con el momento funcional, a fin de que la asamblea sea concilio, instrumento fiel de la infalible Verdad». (O. Clément, L'Église orthodoxe (PUF, Paris $\left.{ }^{6} 1998\right), 81-85$ ). 
nocida; examen y decisión que implica tanto la realización de concilios -especialmente concilios ecuménicos-, como igualmente la acogida de los fieles» ${ }^{45}$. «La recepción es, en última instancia, espontánea» ${ }^{46}$.

La Iglesia de la Reforma, en cambio, al «rechazar cualquier clase de infalibilidad» en alguno o en la totalidad de los miembros de la Iglesia, «la única instancia que puede legitimar el proceso de recepción es la sagrada Escritura», claro que adecuadamente interpretada. En ese sentido «la recepción se desarrolla bajo ciertas condiciones que tienen que ver con la enseñanza de los reformadores y las confesiones de fe que de allí nacieron». «Pero ellas serán siempre relativas, ya que toda confesión encuentra su norma última en la verdad cristiana que se expone en las sagradas Escrituras» ${ }^{47}$. Aquí también, al igual que en la teología ortodoxa, necesitamos una mayor reflexión acerca de cómo se lleva a cabo dicha recepción.

Por último tenemos que decir que todo el desarrollo teológico que desembocó en la convocación del Concilio Vaticano II, trajo consigo indirectamente una nueva reflexión sobre este elemento eclesial básico de la recepción. El mismo hecho de convocar a un concilio motivó a un estudio renovado de la noción teológica de concilio, la cual incluye todo su proceso de recepción, como también la acogida y re-recepción de los concilios anteriores por él mismo ${ }^{48}$. Encontramos, de hecho, en los do-

45 H. Fischer, «Rezeption, Kirchliche II» : Theologische Realenzyclopädie 29, 146. «La Tradición no se reduce a una simple interpretación de las Escrituras. Como Espíritu crítico de la Iglesia, ella discierne los grados de verdad o los símbolos justos que pueden contener los apócrifos de los tiempos apostólicos, y que la liturgia y la iconografía utilizan. Anima y transforma en "cristófera" todas las expresiones de la revelación que presenta la vida "mistérica" de la Iglesia, y particularmente los signos, símbolos y ritos que san Basilio llamaba "dogmas" secretos. Ella se expresa en los testimonios de una justa recepción de la Verdad, es decir, en la tradición doctrinal, litúrgica e iconográfica de la Iglesia. Se identifica por último, con la asimilación vivificante de la Verdad por los santos, cuyo ejemplo e intersección constituyen una especie de Testamento del Espíritu» (O. CLÉment, L'Église orthodoxe (PUF, Paris $\left.\left.{ }^{6} 1998\right), 80\right)$.

46 W. Rusch, Reception, 52.

47 H. Fischer, «Rezeption, Kirchliche II»: Theologische Realenzyclopädie 29, 146. Cf. Cf. W. Rusch, Reception, 45-49.

La Constitución Lumen gentium afirma, con respecto a algunas disposiciones pastorales «acerca de la unión vital con nuestros hermanos en la gloria del cielo y con los que todavía se purifican después de su muerte», que "propone de nuevo los decretos de los sagrados Concilios II de Nicea, de Florencia y de Trento» (LG 
cumentos del Vaticano II -además de los casos recién mencionados en nota de rursus proponit-, varios casos de re-lectura de enseñanzas anteriores, que manteniéndose iguales en lo sustancial, se enmarcan en un horizonte nuevo y más amplio, que de hecho acrecienta (=complementa) la enseñanza precedente: el primado entendido ahora desde la colegialidad episcopal (LG cap. III); el extra Ecclesiam nulla salus entendido ahora como Ecclesiam hanc peregrinantem necessariam esse ad salutem (LG 14); el sacerdocio ministerial entendido ahora desde el servicio al sacerdocio común de los fieles (LG 10); la libertad religiosa valorada ahora desde los derechos propios de la dignidad humana y de la libertad del acto de fe (Dignitatis humanae); el reconocimiento de «lo bueno y verdadero» que hay en otras religiones como «un don de Aquel que ilumina a todos los hombres para que puedan tener finalmente vida» (LG 16) ${ }^{49}$. Se podrían poner otros ejemplos. Se habla también de que «no existe concilio ecuménico si el sucesor de Pedro no lo ha aprobado o al menos aceptado como tal» (LG 22), recordando precisamente lo ocurrido en alguno de los primeros concilios ecuménicos (cf. igualmente CD 4). Se muestra con eso que el tema de la recepción (=aceptación) se da también en la cabeza, con lo cual se entiende en (=el resto de) la Iglesia como todo menos que pasiva obediencia. Especialmente relevantes me parecen dos textos que afirman «indirectamente» este carácter eclesial básico y fundante de la recepción: LG 12:

"La totalidad de los fieles [...] no puede equivocarse en la fe [...] cuando desde los obispos hasta el uiltimo de los laicos cristianos muestran estar totalmente de acuerdo en cuestiones de fe y de moral. El Espíritu de la verdad suscita y sostiene ese sentido de la fe. Con él, el Pueblo de Dios, bajo la dirección del magisterio [...] se adhiere indefectiblemente a la fe transmitida [...], la profundiza con un juicio recto y la aplica cada día más plenamente en la vida»

\section{8:}

«La Iglesia con su enseñanza, su vida, su culto, conserva y transmite a todas las edades lo que es y lo que cree. Esta Tradición apostólica va creciendo en la Iglesia con la ayuda del Espíritu Santo; es decir, crece

51). Lo mismo se puede decir del cap. III de LG, en donde el «sagrado Sínodo, en continuidad con el Vaticano I, enseña y declara con él que [...], propone de nuevo [...]» (LG 18). Cf. también GS 91.

49 En lo sustancial de este párrafo sigo a A. Antón, La “recepción” en la Iglesia, $440-445$ 
la comprensión de las palabras e instituciones trasmitidas cuando los fieles las contemplan y estudian repasándolas en su corazón y cuando comprenden internamente los misterios que viven, cuando las proclaman los obispos, sucesores de los Apóstoles en el carisma de la verdad. La Iglesia camina a través de los siglos hacia la plenitud de la verdad».

Como se puede ahora comprender fácilmente, a partir de los ejemplos recién mencionados, el Concilio Vaticano II trajo de vuelta el tema de la recepción al comprender a la Iglesia de manera más completa, y al mostrarnos que la recepción, como realidad eclesial, «no puede ser reducida a una determinación jurídica, ni de parte de la autoridad, ni de parte de los fieles» ${ }^{50}$. Es fe vivida. Lo anterior nos muestra igualmente que está íntimamente relacionada con una comprensión más acabada de lo que es la Tradición, porque recepción es finalmente «acuerdo con la tradición apostólica» ${ }^{51}$; pero también de una comprensión más mistérica de la Iglesia, que incluye «el organismo social de la Iglesia que está al servicio del Espíritu de Cristo" (LG 8) y una multitud de carismas «que contribuyen a renovar y construir más y más la Iglesia» (LG 12). De igual modo una auténtica comprensión de la recepción implica entender el lugar del magisterio en la vida de la Iglesia, de sus enseñanzas en diversos grados que, en todo caso, implican «el obsequio religioso de la inteligencia y de la voluntad» (LG 25); como también el lugar y el modo de la crítica (=discernimiento común) en y desde la Iglesia. La participación del pueblo santo de Dios del carácter profético de Cristo, que implica un sentido sobrenatural de la fe y su relación con la Iglesia entendida como koinonía, comunión universal y de iglesias particulares; que implica además la presencia del Espíritu Santo que «enseña recordando las palabras de Jesús» (Jn 14,26) y "conduce a los discípulos a la verdad completa» (Jn 16,13) obliga nuevamente a una reflexión más profunda acerca de cómo se acoge esta verdad y se vive de manera auténticamente fiel. Como se puede apreciar la rica enseñanza del Concilio Vaticano II, en su desarrollo eclesiológico, implicaba una renovada y más adecuada manera de comprender la recepción como realidad eclesiológica $^{52}$. Eso es lo que está en desarrollo actualmente en la teología católica y ecuménica.

50 Th. Rausch, Reception Past and Present, 501.

51 Th. Rausch, Reception Past and Present, 504.

52 Cf. W. BeInert, Die Rezeption und ihre Bedeutung für Leben und Lehre der Kirche, 36-44. 


\section{Recepción del Concilio Vaticano II: hechos y hermenéutica}

Por todo lo cual no es de extrañar, en absoluto, el debate actual acerca de cuál es la "auténtica» hermenéutica del Vaticano II. Es simplemente un problema de recepción, que tiene muchas aristas y que están todas en desarrollo. Lo importante es mantenerlas todas en su enriquecedora tensión. A fin de cuentas, es un tema de eclesiología. Todo concilio ha tenido un proceso de recepción, y este también ${ }^{53}$. De modo que una cosa es comprender bien qué es recepción y cuáles son sus aspectos; y otra es cómo «recepcionamos», en cada una de las circunstancias geográficas e históricas actuales, este concilio en particular. Ambas cosas están unidas, pero es necesario darse cuenta que ambas están en juego. Y esto no es banal.

Si miramos, aunque muy brevemente -casi esquemáticamente-, los elementos y posibles etapas que se han desarrollado en la recepción del Concilio Vaticano II, lograremos comprender mejor este multifacético proceso que es la recepción. Podemos observarlo desde los hechos históricos más relevantes, y desde los caminos de la reflexión teológica ${ }^{54}$.

Entre los hechos históricos más importantes, luego de la eclosión teológico-pastoral que significó el tiempo del Concilio y sus años inmediatamente posteriores ${ }^{55}$, con toda la transformación estructural que se llevó a cabo, tanto a nivel particular como universal, tenemos un primer intento de síntesis magisterial en la Exhortación Apostólica Evangelii nuntiandi, del Papa Pablo VI en el año 1975, que refleja un fruto maduro de todo el esfuerzo de su pontificado por llevar adelante la preocupación pastoral del mismo concilio: «Evangelizar constituye, en efecto, la dicha y vocación propia de la Iglesia, su identidad más profunda» (EN 14). La llegada del Papa Juan Pablo II a la sede de Pedro estuvo marcada por el deseo de conducir a la Iglesia hacia el tercer milenio también a partir de las enseñanzas del Concilio ${ }^{56}$. Pero en ese pontificado se veri-

53 Cf. G. Alberigo, La condición cristiana después del Vaticano II, en G. Alberigo J.-P. Jossua (eds.), La recepción del Vaticano II (Cristiandad, Madrid 1987) 19-24.

54 Una breve historia de la recepción del Concilio en Сн. Tнеовадd, La réception du concile Vatican II. I. Accéder à la source (Cerf, Paris 2009), 547-654.

55 Se puede afirmar que, habiendo múltiples frutos del Concilio, ha sido la reforma litúrgica la más visible, y en muchos sentidos también la más relevante, ya que la liturgia representa lo que la Iglesia cree y vive.

56 Cf. Redemptor hominis 2-5. 
ficaron dos hechos que marcaron este desarrollo de manera importante, en el sentido de una decantación de la teología conciliar en lo institucional: La elaboración del Código de Derecho Canónico, en el año 1983, y el Catecismo de la Iglesia Católica, en el año 1992. Ambos documentos representaron, respectivamente, una renovación del antiguo código del año 1917 y del Catecismo Romano, elaborado luego del Concilio de Trento; y querían ser una recta interpretación del Vaticano II, es decir, una puesta en práctica de sus enseñanzas en la legislación canónica, a partir de la autocomprensión de la Iglesia que muestran los documentos conciliares; $y$ una puesta en práctica en la catequesis, en cuanto compendio de la doctrina católica, comprendida desde la actual situación del mundo. Más allá de la permanente discusión acerca de la continuidad que muestran con la enseñanza del Concilio ${ }^{57}$, los tres documentos anteriormente mencionados representan una toma de posición magisterial acerca de la recepción del concilio Vaticano II en la Iglesia, y como tal, son parte importante de este proceso de recepción de toda la Iglesia en todos sus miembros. Muestra con claridad que la recepción se ha llevado a cabo en todos las estructuras de la Iglesia, cada cual desde su lugar.

Un papel importante, junto a la Encíclica Populorum progressio (Pablo VI, 1967) y los diversos sínodos de los obispos, tuvo también la Segunda Asamblea Extraordinaria del Sínodo de los Obispos, en el año 1985, convocado precisamente por el Papa Juan Pablo II con ocasión del vigésimo aniversario de la clausura del Concilio. «Objetivo de esa asamblea era dar gracias y celebrar los frutos espirituales del concilio Vaticano II, profundizar su enseñanza para lograr una mayor adhesión a la misma y difundir su conocimiento y aplicación» (Juan Pablo II en Fidei depositum 1). Se hizo famosa su interpretación: «La eclesiología de comunión es la idea central y fundamental en los documentos del Concilio" (Relatio finalis II,C,1), y entregó incluso algunos criterios para una más profunda recepción del Concilio (cf. I,5). Se puede decir entonces que desde el año 1985 en adelante, el tema de la recepción del Concilio y cuál ha de ser su verdadero modo de ponerlo en práctica se transformará paulatinamente en un tema de explícita reflexión. Un rol

57 Por ejemplo, con respecto al CIC, cf. E. Conecco, «La recepción del Vaticano II en el Código de Derecho Canónico», en G. Alberigo - J. P. Jossua (eds.), La recepción del Vaticano II, 299-354; B. J. Hilberath, Der Codex Iuris Canonici als authentische Rezeption des Zweiten Vaticanums?, en Rottenburger Jahrbuch für Kirchengeschichte 26 (2007) 36-39. 
también importante ha tenido el Papa Benedicto XVI. Cuando teólogo y luego Prefecto de la Congregación para la Doctrina de la Fe, era ya un tema que había abordado ${ }^{58}$, pero al asumir como Romano Pontífice, ese tema se hace aún más explícitamente un tema del magisterio supremo. En ese sentido fue clásico su Discurso a los cardenales, arzobispos, obispos y prelados superiores de la curia romana (Roma, 22 de diciembre de 2005), en donde, a cuarenta años del Concilio, se pregunta: «¿Cuál ha sido el resultado del Concilio? ¿Ha sido recibido de modo correcto? En la recepción del Concilio, ¿qué se ha hecho bien?, ¿qué ha sido insuficiente o equivocado?, ¿qué queda aún por hacer?», en donde él mismo también plantea su propio punto de vista: Una "hermenéutica de la reforma, de la renovación dentro de la continuidad del único sujeto-Iglesia, que el Señor nos ha dado; es un sujeto que crece en el tiempo y se desarrolla, pero permaneciendo siempre el mismo, único sujeto del pueblo de Dios en camino».

En el campo ecuménico y del diálogo interreligioso el Concilio ha influido de manera determinante y su recepción ha sido bastante fructífera. Uno de los objetivos de su convocación fue precisamente la esperanza de «rehacer aquella unidad visible de todos los cristianos que responda a los deseos del Redentor divino» (Juan XXIII, Humanae salutis 8, 1961), hecho apoyado por la creación del Secretariado para la Unión de los Cristianos, en 1960, por el mismo Papa Juan XXIII. Por eso, en los años posteriores al Vaticano II, se han llevado a cabo importantes diálogos a nivel teológico, con unos primeros logros no siempre fáciles ${ }^{59}$, y con un fruto importante en la Carta Encíclica del Papa Juan Pablo II, $U t$ unum sint (1995). Habría que agregar, igualmente, todo el desarrollo en el campo del diálogo interreligioso, fruto de los decretos Nostra aetate y Dignitatis humanae, que han desembocado, entre otras cosas, en el acontecimiento inédito del Encuentro Mundial en Asís de representantes de todas las religiones del mundo (1986), convocado por el mismo

58 Cf., por ejemplo, J. Ratzinger, Theological Highlights of Vatican II (Paulist Pres, New York 1966), en donde se presentan sus cuatro clásicos balances, elaborados al cabo de cada sesión; Mi vida. Recuerdos (1927-1977) (Encuentro, Madrid ${ }^{5} 2005$ ), 141-153.

59 Se puede mencionar, por ejemplo, el diálogo con la Comunión Anglicana que llevó a la creación, en 1970, de la Anglican Roman Catholic International Comission (ARCIC), y los diálogos con la Comunión Luterana, que desembocaron en la Declaración Conjunta sobre la Doctrina de la Justificación, en 1999. 
Papa Juan Pablo II, para estar juntos y rezar por la paz, cada uno desde su propia realidad de $\mathrm{fe}^{60}$.

Evidentemente, todo esto no es solo un tema de la Iglesia universal, sino también y muy fuertemente de las iglesias particulares. No podemos siquiera esbozar aquí todo el desarrollo que ha habido en este campo en las distintas regiones y países ${ }^{61}$. A modo de ejemplo paradigmático, recordemos que en Latinoamérica ha habido dos desarrollos muy interesantes: La realización -post-conciliar- de las cuatro Conferencias Generales del Episcopado Latinoamericano y del Caribe, particularmente la realizada en Medellín en el año 1968, que explícitamente «se encaminó hacia la búsqueda de una nueva y más intensa presencia de la Iglesia en la actual transformación de América Latina, a la luz del Concilio Vaticano II» (Introducción). Al mismo tiempo y con igual objetivo se desarrolló en una parte importante de la reflexión teológica latinoamericana una corriente de pensamiento que -a pesar de sus diferencias- se identifica bajo el nombre de Teología de la Liberación. "Como experiencia fundante de la Teología de la Liberación estaba el llamado y la puesta en práctica del Concilio Vaticano II de la apertura al mundo en el cual la Iglesia debe actuar como sacramento de salvación ${ }^{62}$. Es el descubrimiento de la presencia del «otro», a la que el Vaticano II nos invita a estar más atentos y la realización de teologías más conscientemente «situadas». Análogamente se puede observar este mismo fenómeno de encuentros episcopales generales, a fin de reflexionar en la puesta en práctica del Concilio, y de teologías contextuales en general, como expresión de apertura a los signos de los tiempos propuestos por el Vaticano II, en todas las grandes iglesias particulares del mundo católico ${ }^{63}$. Esto ha sido un ma-

60 Cf. Сh. Theobald, La réception du concile Vatican II, 611-628.

61 Cf., por ejemplo, P. C. Phan, «Reception of Vatican II in Asia: Historical and Theological Analysis», en Gregorianum 83 (2002) 269-285; J. CHINICI, «Reception of Vatican II in United Stated", en Theologiacal Studies 64 (2003) 461-494; G. Routhier (ED.), Réceptions de Vatican II. Le concile au risqué de l'histoire et des espaces humains (Peeters, Louven 2004). M. FaGgioli, "Council Vatican II: Bibliographical Overview 2007-2010», en Cr St 32 (2011) 788-789.

62 Cf. R. Oliveros, «Historia de la teología de la liberación», en Mysterium Liberationis, I, 18.

63 Se podrían estudiar los documentos de las conferencias continentales de los episcopados como el Simposio de las Conferencias Episcopales de África y Madagascar (SECAM), o la Federation of Asian Bishops' Conferences (FABC). Igualmente se 
nifiesto fenómeno de recepción como experiencia eclesial particular con sus propias acentuaciones, conflictos, correcciones, adaptaciones, y a fin de cuentas, desarrollo y crecimiento. La auténtica «interpretación» del Concilio pasará por la aceptación y acogida de cada recepción particular como una verdadera interpretación y recepción. Podríamos todavía hablar de una multitud de nuevos movimientos, corrientes, iniciativas, carismas, caminos, estructuras vitales, comunidades, etc., los cuales cada uno a su modo y acentuando diversas cosas, se reconocen como puesta en práctica de las acentuaciones eclesiológicas del Vaticano $\mathrm{II}^{64}$. Su misma inserción -no siempre fácil- en la iglesia particular y universal es un proceso de recepción, que es parte de la recepción más global del Concilio, pero a la vez más que una simple aplicación del Concilio. La Iglesia es más que el Concilio.

Mas igualmente, a nivel más bien sectorial y más minoritariamente, pero no menos apreciable, encontramos fenómenos de no-recepción del Concilio. El ejemplo más claro es la toma de posición del Obispo Marcel Lefebvre, ya en el Concilio mismo, y luego paulatina y más violentamente, hasta desembocar en el cisma del año $1988^{65}$. Lo que aparecía como un tema en torno a la liturgia y a aspectos más externos de la Tradición, era en realidad el rechazo a un contenido que había recibido un desarrollo notable durante los debates conciliares, como fue el argumento de la libertad religiosa, comprendida ahora a partir de la dignidad humana y de la libertad de conciencia propia del acto de fe ${ }^{66}$. Aquí nos encontramos con el rechazo "en nombre de la Tradición" " a un desarrollo importante de la conciencia cristiana. Con esto vemos un ejemplo de lo complejo que puede ser la recepción, al tener que compaginar la Tradición con los desarrollos teológicos que surgen a la luz de las nuevas

puede revisar todo el desarrollo y entrada al catolicismo de la "teología negra», la "teología asiática» o la "teología feminista», desarrollos impensables sin el empuje del Vaticano II y su apertura a los signos de los tiempos: «Para cumplir esta tarea, corresponde a la Iglesia el deber permanente de escrutar a fondo los signos de los tiempos e interpretarlos a la luz del evangelio" (GS 4).

64 Cf. F. González, Los movimientos en la historia de la Iglesia (Encuentro, Madrid 1999). También toda la vida y conciencia de las Comunidades Cristianas (Eclesiales) de Base, en Latinoamérica, como una forma de vivir la eclesialidad inserta en el mundo.

65 Cf. Juan Pablo II, Carta Apostólica Ecclesia Dei (2 de julio de 1988).

${ }_{66}$ Cf. Declaración Dignitatis humanae, sobre la libertad religiosa. 
formas de comprensión del mundo, a la vez que muestra palmariamente que un diverso concepto de recepción implica una diversa forma de comprensión de la misma fe.

En síntesis, a nivel de hechos, se da una multitud factores de diversa envergadura, que se relacionan con diversos aspectos de la recepción y que constituyen todos juntos la gran recepción del Concilio. Los diversos caminos se complementan y se necesitan mutuamente.

Dentro de este gran proceso de recepción multifacético, se ha dado también una discusión teológica sobre lo que dijo y pidió el Concilio, al encontrarnos, luego de cincuenta años, en un nuevo horizonte de comprensión. Es una discusión hermenéutica y tiene también diversas perspectivas ${ }^{67}$. En los años del Concilio y los inmediatamente posteriores, estando vivos y activos sus protagonistas, fueron importantes las crónicas de las sesiones y los comentarios a los textos elaborados, además de los estudios y publicación de las fuentes conciliares ${ }^{68}$. Un ejemplo de crónicas es la clásica obra de G. Caprile, presentada en la Rivista Civiltà Cattolica durante los años conciliares ${ }^{69}$. Con respecto a los comentarios, se elaboraron fundamentalmente dos tipos: unos más «exegéticos», que explicaban cada número de cada texto ${ }^{70}$, y otros más temáticos, en torno a los núcleos fundamentales de la enseñanza conciliar ${ }^{71}$; además de los innumerables estudios monográficos sobre obispos, teólogos, personajes que participaron de manera especial en el Concilio, grupos de pensamiento, órdenes religiosas, iglesias locales y su aggiornamento, temas más

${ }^{67}$ Muy útiles los boletines bibliográficos de M. FAGGioli: "Concilio Vaticano II: bollettino bibliográfico (2000-2002)», en Cr St 24 (2003) 335-360; "Concilio Vaticano II: bollettino bibliográfico (2002-2005)», en Cr St 26 (2005) 743-767; «Council Vatican II: Bibliographical Overview 2005-2007», en Cr St 29 (2008) 567-610; "Council Vatican II: Bibliographical Overview 2007-2010», en Cr St 32 (2011) 755-791.

68 Así encontramos, junto a las Acta Synodalia y la Editio typica, la publicación de alguna Synopsis, Index verborum, Concordantia, etc.

69 Cf. G. Caprile, Il Concilio Vaticano II. Cronache del Concilio Vaticano II edite da "La Civiltà Cattolica" a cura di Giovanni Caprile S.I., 5 Vol., (Ed. La Civiltà Cattolica, Roma 1968).

70 Cf. Lexicon für Theologie und Kirche: Das zweite vatikanische Konzil, 3 Bde. (Herder, Freiburg im Breisgau 1966).

71 Cf. G. Baraúna (ED.), La Iglesia del Vaticano II. Estudios en torno a la Constitución conciliar sobre la Iglesia (Juan Flors, Barcelona ${ }^{3} 1968$ ). 
relevantes y nuevos, aplicaciones en la base, etc. ${ }^{72}$. Como era previsible, al cabo de 40 años, comenzaron a aparecer nuevos comentarios generales, ahora redactados en un nuevo contexto eclesial y mundial, lo cual implica nuevas lecturas del mismo Concilio ${ }^{73}$. Los sucesivos aniversarios de las grandes constituciones también han sido ocasión para re-leer los textos conciliares ${ }^{74}$. Con el pasar de los años, surgieron también nuevas líneas investigativas. Una que merece especial atención es la historiografía del Concilio. No es tarea fácil escribir la historia de un acontecimiento tan complejo como fue el Concilio Vaticano II, pero no por eso no se debe emprender esa magna obra. Por esa razón el trabajo de G. Alberigo y su equipo se ha transformado en una obra clásica, hoy la más completa y de la cual no se puede prescindir ${ }^{75}$. Pero como toda obra histórica es también interpretativa y, por lo tanto, susceptible de críticas y de miradas diferentes a esos mismos acontecimientos ${ }^{76}$. Será precisamente el aumento de estudios históricos -en el entendido que cumplan con las normas de seriedad científica- el que nos irá ayudando a comprender cada vez con mayor «objetividad» lo que el Concilio «dijo» desde el hoy de la historia. En el último tiempo se han multiplicado las publicaciones de los diarios personales y cartas de los protagonistas del Concilio, ya casi todos fallecidos, de modo que desde esa ventana uno puede percibir el «espíritu» que animaba las reformas y orientaciones conciliares, a fin de comprenderlas mejor y aplicarlas hoy más adecuadamente ${ }^{77}$. Todos estos estudios son un aporte para comprender y acoger debidamente el

72 Cf. M. FAggroli: Concilio Vaticano II: bollettino bibliográfico (2000-2002), 344-357.

73 Cf. B. J. Hilberath - P. Hünermann (Hrsg.), Herders Theologischer Kommentar zum Zweiten Vatikanischen Konzil, 5 Bde., (Herder, Freiburg 2004-2006).

74 Cf. M. Faggioli, «Concilio Vaticano II: bollettino bibliográfico (2002-2005)», 753-760; "Council Vatican II: Bibliographical Overview 2005-2007», 594-602.

75 G. Alberigo (Dir.), Storia del concilio Vaticano II, 5 vol., (Peeters, Leuven 1995-2001).

76 Cf. A. Marchetto, Il Concilio Ecumenico Vaticano II. Contrappunto per la sua storia (Editrice Vaticana, Città del Vaticano 2005).

77 Cf., entre tantos otros, Y. Congar, Mon Journal du Concile, 2 Vol., (Ed. du Cerf 2002); L. Declerck, Les agendas conciliaires de Mgr. J. Willebrands, secrétaire du Secré-tariat pour l'Unité des Chrétiens (Peeters, Leuven 2009); H. Camara, Circulares Interconciliares (CEPE, Recife 2008); H. DE Lubac, Carnets du Concile, 2 vol. (Ed. du Cerf, Paris 2007). 
Vaticano II, y a la vez, son una forma de recibirlo e influir en su recepción general.

En medio de este mar de publicaciones se pueden percibir algunas líneas de trabajo y, especialmente, ciertos criterios que se han ido elaborando para comprender y «vivir» el Concilio. En esto se han abierto importantes debates teológicos acerca del tenor de los documentos conciliares. Siempre a modo de simple ejemplo podemos mencionar algunos temas: ¿Qué involucra considerar el Concilio como un "evento", en donde «algo sucedió»? (Escuela de Bologna). Los documentos nacen en un contexto "espiritual» que se prolonga en el tiempo: ¿Qué implica eso a la hora de interpretar actualmente los textos? ${ }^{78}$. Hay quienes descubren un camino de comprensión en la interrelación entre los textos conciliares y su historia durante el desarrollo del Concilio, incluidos todos los acontecimientos que en esos momentos vivía la Iglesia, tanto dentro del Concilio, como ad extra. En particular, su intención pastoral (Ch. Theobald $)^{79}$. También se habla de los Documentos del Vaticano II como un "texto constitucional», en donde fungen como principios o criterios hermenéuticos para saber qué cosas hoy son -análogamente- «constitucionales» y qué cosas «inconstitucionales» en la vida de la Iglesia (Hünermann) ${ }^{80}$. En el mundo anglófono se ha reflexionado sobre las consecuencias del nuevo "estilo» de presentar la doctrina en el Vaticano II (O’Malley). Ese «espíritu del Concilio» ¿es un simple sentimiento o forma exterior?, ¿o está mostrando un nuevo "modo" de ser Iglesia y con eso una nueva eclesiología? Un nuevo estilo traerá consecuencias teológicas también, ¿cuáles? La lectura de sus documentos debe corresponder entonces a su estilo ${ }^{81}$. En cambio, en otros sectores del mundo, incluido Latinoamérica, el tema se está trasladando desde la búsqueda

78 La gran obra de G. Alberigo (Dir.), Storia del concilio Vaticano II, como fruto de largos años de investigación, representa una clara toma de posición en este sentido. Cf. también J. Комолснак, Vatican II as an 'event', en TD 46,4 (1999) 337-352.

79 Сн. Theоваld, Enjeux herméneutiques des débats sur l'histoire du concile Vatican II: Cr St 28 (2007) 359-380.

80 P. Hünermann, Der Text: Werden - Gestalt - Bedeutung. Eine hermeneutische Reflexion, en B. J. Hilberath - P. Hünermann (Hrsg.), Herders Theologischer Kommentar zum Zweiten Vatikanischen Konzil, 5-101; Der "Text". Eine Ergänzung zur Hermeneutik des II. Vatikanischen Konzils, in Cr St 28 (2007) 339-358.

81 J.W.O'Malley, What Happenedat Vatican II (Harvard University Press, Cambridge, MA 2008); «Vatican II: Did Anything Happen?», en Theological Studies 67 (2006) 3-33. 
de una interpretación auténtica del Concilio a una teología que se haga "de acuerdo al Concilio», pero más allá del Concilio, habida cuenta de los nuevos contextos culturales. Hay temas nuevos, ¿cómo los trataría hoy el Vaticano II?82. Por eso no son pocas las ocasiones en donde se escucha hablar de un «Vaticano III». Esa es también una «palabra» sobre la «recepción» del Vaticano II. Podemos mencionar también el debate que se ha dado frente a la distinción presentada por el Papa Benedicto XVI entre una hermenéutica de la discontinuidad y de la ruptura y una hermenéutica de la reforma ${ }^{83}$. Allí se trata de comprender equilibradamente la permanente tensión entre continuidad y discontinuidad (ambas presentes en todo concilio), tensión en la cual entran todos los temas que ya hemos mencionados acerca del texto y el acontecimiento, que puede ser interpretado como un nuevo Pentecostés, según las palabras de Juan XXIII en la convocación del Concilio (Humanae salutis, 21) ${ }^{84}$.

Como se puede apreciar, el debate en torno a la hermenéutica de los documentos y acontecimiento del Vaticano II es parte del proceso de recepción del mismo Concilio ${ }^{85}$. En efecto se trata, por una parte, de comprender, interpretar y aplicar los textos conciliares, pero de tal manera que no es posible una sin las otras (se interpreta aplicando, o se comprende interpretando); $y$ de otra parte, teniendo en cuenta tanto el autor, como los mismos documentos y comunidades que hoy intentan comprender, interpretar y aplicar esos textos. Un texto, mientras no ha sido comprendido y acogido por un receptor, es decir, no ha sido recibido, no ha cumplido todavía su objetivo y está, en realidad, muerto ${ }^{86}$. Podríamos hablar entonces de una hermenéutica de la recepción ${ }^{87}$. Al mismo tiempo se han de comprender los textos como un todo armó-

82 Temas como la inculturación, la teología india, la ecología, no pueden simplemente ser «deducidos» de las enseñanzas conciliares.

83 Cf. M. L. Lamb - M. Levering (Eds.), Vatican II. Renewal within Tradition (Oxford, New York 2008).

84 Un buen reporte bibliográfico sobre estos debates hermenéuticos en M. FAGGioli, "Council Vatican II: Bibliographical Overview 2005-2007», 570-587; «Council Vatican II: Bibliographical Overview 2007-2010», 757-777.

85 Para este párrafo cf. O. Rush, Still Interpreting Vatican II. Some Hermeneutical Principles (Paulist Press, New York 2004).

O. Rush, Still Interpreting Vatican II, 55.

87 O. Rush, Still Interpreting Vatican II, X-XI. 
nico y completo (es «el» Vaticano II) ${ }^{88}$, pero a la vez, cada documento tiene su propia importancia y objetivo, y cada uno es diverso en su hondura, estilo, género literario y vocabulario, su lugar en la jerarquía de verdades y el nivel magisterial que representa. Al menos se pueden distinguir el sentido y la fuerza de una constitución dogmática, una constitución pastoral, una constitución, un decreto o una declaración. Además es necesario ver las estructuras internas de los documentos y su lugar dentro del todo. Nos podemos preguntar si existen ejes temáticos o intencionales que determinen la interpretación del conjunto. ¿Qué puede significar para su interpretación el que se defina como un «concilio pastoral» con una preocupación ecuménica? Igualmente cada texto tiene su propia historia textual, como a su vez una historia posterior de influencia, en donde nuevas síntesis son exigidas a la hora de comprender tanto las posibles «yuxtaposiciones» encontradas en el texto, como las diversas interpretaciones y recepciones de los mismos textos, en las cuales se deben mantener las tensiones propias de la realidad plural ${ }^{89}$. La pre- y post-historia forman parte de su «significado»" ${ }^{90}$. Hay también intertextualidad e intratextualidad, en donde un texto se comprende en relación a otros semejantes, de manera diacrónica y sincrónica ${ }^{91}$. Todo ello ha de ser tenido en cuenta para una auténtica recepción del Vaticano II. Finalmente uno se puede preguntar, ¿y qué es un concilio? Diversas respuestas nos darán también diversas interpretaciones de sus textos y diversas recepciones en la vida ${ }^{92}$. Tenemos todavía un largo y esperanzador camino por delante.

88 Cf. Sinodo de los Obispos de 1985, Relatio finalis I, 5.

O. Rush, Still Interpreting Vatican II, 64-65.

Cf. G. Routhier-G. Jobin (Dir..), L’Autorité et les Autorités. L’herméneutique théologique de Vatican II (Cerf, Paris 2010).

91 Cf. O. Rush, Still Interpreting Vatican II, 40-48.

92 Cf. G. Ruggieri, «Recezione e interpretazioni del Vaticano II. Le ragioni di un dibattito", en Cr St 28 (2007) 381-406. 
Resumen: Este artículo es un estudio sobre el significado teológico del concepto de «recepción»y su aplicación en el caso del Concilio Vaticano II. El texto comienza con una definición de lo que teológicamente y desde la perspectiva católica se puede entender como recepción, para luego profundizar brevemente en alguno de los diversos aspecto de este fenómeno multifacético: recepción en la Sagrada escritura (AT y NT), recepción en la historia de los concilios ecuménicos, reducción paulatina del significado del concepto en el segundo milenio y recuperación en la teología del Concilio Vaticano II.

Se aplica luego a la situación del Concilio Vaticano II, recordando los momentos históricos más relevantes en este proceso desde su culminación hasta nuestros días. Se termina con una breve exposición de los criterios y desafíos hermenéuticos que se han ido elaborando en estos cincuenta años de recepción, a partir de un sucinto recorrido bibliográfico.

Palabras clave: Concilio, Vaticano II, recepción, recibir, hermenéutica.

Abstract: The present paper offers a study on the theological meaning of the concept reception and it's use in the Second Vatican Council documents. It opens with a theological definition of the concept from the catholic standpoint to continue with other aspects of this complex phenomenon: the reception of the Holy Scripture, of the Ecumenical Councils, the narrowing of the concept during the second millennium and its recovery by the Second Vatican Council's theology.

The study looks then to the development of the concept after Vatican II and finishes with a short explanation on hermeneutical considerations developed during these fifty years of reception according to a brief bibliography.

Keywords: Council, Vatican II, reception, receive, hermeneutics. 
